of the relation between use of NSAIDs and gastrointestinal adverse reactions were reported. The first examined data based on "yellow card" reporting in the United Kingdom for the first five years of

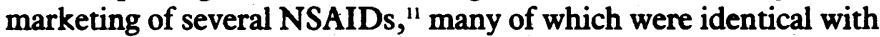
those compared in our study. The Committee on Safety of Medicines concluded that piroxicam fell into a group of 12 NSAIDs for which differences in safety "... . cannot be clearly distinguished from each other based on yellow card reports." The second study compared five NSAIDs, only one of which (piroxicam) was included in this study, in an innovative postmarketing surveillance scheme, prescription event monitoring. ${ }^{12}$ That study examined a wider range of adverse events than either our study or that of the Committee on Safety of Medicines, but the findings relating to the events affecting the gastrointestinal system were interpreted as reflecting no noteworthy differences between the drugs examined. Thus it seems reasonable to conclude that large and clinically important differences in rates of upper gastrointestinal bleeding, perforation, and ulcer between piroxicam and the rest of the NSAIDs probably do not exist.

We thank Deanne Knapp and Carlene Baum for their technical help in preparing and interpreting information on drug use; Greg Brolund, Joan Gurian, Kem Phillips, and Carolyn Brophy for their computer support;
John Harter and Robert Temple for their helpful discussions; and Marilyn E Ratzkin for preparing the manuscript.

This paper contains our views, which are not necessarily those of the Food and Drug Administration.

\section{References}

1 Fok KH, George PJM, Vicary FR. Peptic ulcers induced by piroxicam. Br Med f 1985;290:117. 2 Beermann B. Peptic ulcers induced by piroxicam. Br Med $\mathcal{J} 1985 ; 290: 789$.

3 Meyer P', Thiis I. Peptic ulcers induced by piroxicam. BrMed f 1985;290:789.

4 O'Brien JD, Burnham WR. Bleeding from peptic ulcers and use of non-steroidal antiinflammatory drugs in the Romford area. BrMed f 1985:291:1609-10.

5 Somerville K, Faulkner G, Langman $M$. Non-steroidal anti-inflammatory drugs and bleeding peptic ulcer. Lancet 1986;i:462-4.

6 Inman WHW, Rawson NSB. Peptic ulcer and piroxicam. Br Med f 1985;290:932-3.

7 Lee $B$, Turner $W$. Food and Drug Administration's adverse drug reaction monitoring program. Am F Hosp Pharm 1978;35:929-32.

8 US Food and Drug Administration. 'COSTART', coding symbols for thesaurus of adverse reaction terms. 2nd ed. Maryland: Food and Drug Administration, 1985.

9 IMS America Ltd. National prescription audit. Ambler, Pennsylvania: IMS America Ltd, 1974-85. ڤ)

10 Weber JCP. Epidemiology of adverse reactions to nonsteroidal anti-inflammatory drugs. In: Rainsford KD, Velo GP, eds. Advances in inflammation research. Vol 6. New York: Raven Press, 1984.

11 Committee on Safety of Medicines. CSM update. Non-steroidal anti-inflammatory drugs and serious gastrointestinal reactions: 2 . Br Med f 1986;292:1190-1.

2 Anonymous. Comparative study of five NSAIDs. Drug Surveillance Research Unit PrescriptionEvent Monitoring News 1985; No 3:3-13.

(Accepted 28 October 1986)

\title{
Low serum selenium concentration and glutathione peroxidase activity in intrahepatic cholestasis of pregnancy
}

\author{
ANTTI KAUPPILA， HEIKKI KORPELA， ULLA-MAIJA MÄKILÄ， ERKKI YRJÄNHEIKKI
}

\begin{abstract}
Serum selenium concentrations were found to be significantly lower in women with intrahepatic cholestasis of pregnancy than in women with normal pregnancies during the last trimester of pregnancy and post partum. The activity of the selenoenzyme glutathione peroxidase had a significant positive correlation with selenium concentration and it was also significantly lower in women with the disease.

These findings suggest that selenium deficiency and reduced glutathione peroxidase activity are associated with the aetiopathogenesis of intrahepatic cholestasis of pregnancy.
\end{abstract}

\section{Introduction}

The aetiology of intrahepatic cholestasis of pregnancy is unknown. Patients with this condition are abnormally sensitive to oestrogens. ${ }^{12}$ Intrahepatic cholestasis of pregnancy is most common in Scandinavia and Chile, ${ }^{1}$ regions whose inhabitants have a low dietary intake of selenium. ${ }^{3}$ Because deficiency of selenium may lead to liver disturbances in animals ${ }^{45}$ and in man $^{6}$ we investigated the importance of selenium in intrahepatic cholestasis of pregnancy by measuring the

University of Oulu, SF 90220 Oulu, Finland

ANTTI KAUPPILA, MD, PHD, associate professor, department of obstetrics and gynaecology

HEIKKI KORPELA, DVM, researcher, department of physiology

ULLA-MAIJA MÄKILÄ, MD, PHD, researcher, department of obstetrics and gynaecology. Dr Mäkilä died last year

Regional Institute of Occupational Health, Oulu, Finland

ERKKI YRJÄNHEIKKI, PHD, chemist

Correspondence to: Professor Kauppila. serum concentration of selenium and the serum activity of the selenoenzyme glutathione peroxidase in pregnant women with and without this disease.

\section{Subjects and methods}

Twelve consecutive patients with intrahepatic cholestasis of pregnancy from the antenatal ward and 12 healthy pregnant women from the outpatient maternity centre were studied (table I). Those with the condition suffered from itching and had increased serum bile acid concentrations and serum aspartate aminotransferase and alanine aminotransferase activities. The : patients and controls were matched for age (within three years) and parity. Because the serum concentration of selenium correlates strongly with nutritional selenium availability, ${ }^{7}$ which varies in Finland according to the time of year, the patients and controls were studied at the same time and were from the same region. Four of the patients but none of the controls had 을 a twin pregnancy. Venous blood samples were taken weekly from the $N$ patients with intrahepatic cholestasis of pregnancy from the 31st to the 37th $\mathrm{G}$ weeks and from the controls from the 30th to the 35th weeks of gestation until the third to fifth days post partum.

Serum selenium concentrations were determined by hydride generation $N$ atomic absorption spectrophotometry and the activity of glutathione $N$ peroxidase by a spectrometric method using t-butyl-hydroperoxide as the $O$ substrate.

In the statistical analyses of the results the changes within the groups were

TABLE I-Clinical characteristics of patients with intrahepatic cholestasis of pregnancy and controls studied

\begin{tabular}{lcccc}
\hline & $\begin{array}{c}\text { Mean (SD) } \\
\text { age } \\
\text { (years) }\end{array}$ & $\begin{array}{c}\text { Range/No of } \\
\text { primiparas }\end{array}$ & $\begin{array}{c}\text { Mean (SD) } \\
\text { gestational age at } \\
\text { delivery (weeks) }\end{array}$ & $\begin{array}{c}\text { No of } \\
\text { pairs of } \\
\text { twins }\end{array}$ \\
\hline $\begin{array}{l}\text { Patients with intrahepatic cholestasis } \\
\text { of pregnancy }(\mathrm{n}=12)\end{array}$ & $\begin{array}{l}28 \cdot 7(5 \cdot 4) \\
\text { Controls }(\mathrm{n}=12)\end{array}$ & $\begin{array}{l}0-3 / 7 \\
0-3 / 7\end{array}$ & $\begin{array}{l}37 \cdot 9(2 \cdot 1) \\
40 \cdot 8(1 \cdot 1)\end{array}$ & \begin{tabular}{c}
4 \\
\hline
\end{tabular} \\
\hline
\end{tabular}


assessed by Friedman's two way analysis of variance and a sign test. A matched pair $t$ test was used in cross sectional comparison of the groups during the 30th-34th, the 35th-37th, and the 38th-4lst weeks of pregnancy and post partum and linear regression analysis for correlation studies of serum selenium concentrations and glutathione peroxidase activities at these different times. The mean of the results within each period (indicated in fig 1) was used in the statistical analyses of the results.

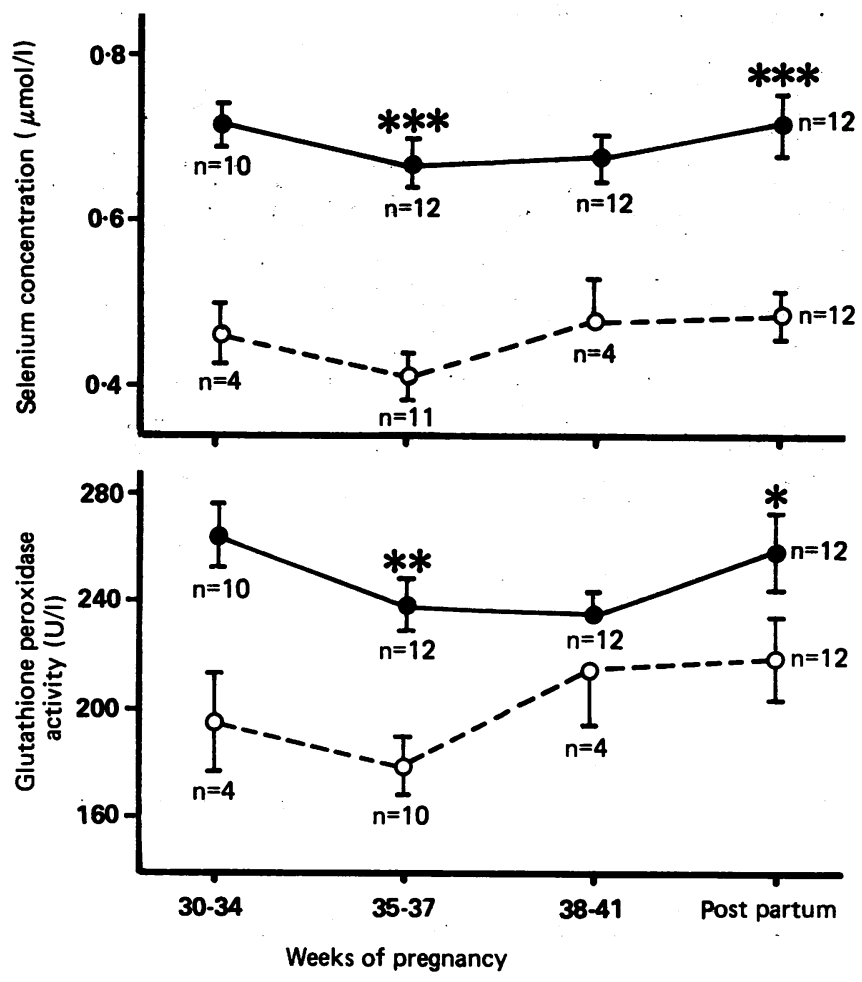

FIG 1-Mean (SEM) serum selenium concentration and glutathione peroxidase activity during different periods in the last trimester of pregnancy and 3-5 days after delivery in patients with intrahepatic cholestasis of pregnancy $\left(\mathrm{O}-\mathrm{-}^{-}-\mathrm{-O}^{-}\right)$ and healthy controls (-). Significance of differences: ${ }^{\star} p<0.05$, ${ }_{\star \star \star} \mathrm{p}<0.01, \star \star \star \mathrm{p}<0.001$.

\section{Results}

The serum selenium concentrations and the serum glutathione peroxidase activities were significantly lower in the patients with intrahepatic cholestasis of pregnancy than in the controls during the 30th-34th and 35th-37th weeks of pregnancy and after delivery but not during the 38th-41st weeks of pregnancy (fig 1). The confidence intervals at the $99 \cdot 9 \%$ confidence level for the difference in serum selenium concentration between the groups with the matched pairs $t$ test were 0.08 to $0.33 \mu \mathrm{mol} / 1$ at $35-37$ weeks of pregnancy and 0.10 to $0.36 \mu \mathrm{mol} / 1$ post partum. Serum selenium concentrations and glutathione peroxidase activities did not differ significantly between women with the condition who had singleton pregnancies and those who had twin pregnancies.

In the control group (evaluated with Friedman's two way analysis of variance test $)$ the concentrations of selenium $(p=0.004)$ and the activities of glutathione peroxidase $(p=0.002)$ differed significantly with time. The posterior sign test showed that serum selenium concentration during weeks 30-34 of pregnancy was significantly higher than during weeks $35-37$ and during weeks 38-41 of pregnancy (table II). With the sign test the activities of glutathione peroxidase during weeks 30-34 were also significantly higher than during weeks 35-37 and weeks 38-41 of pregnancy and lower during weeks 38-41 of pregnancy than post partum. In the group with intrahepatic cholestasis of pregnancy there were no significant differences in serum selenium concentrations and glutathione peroxidase activities with time. (In this group only results from weeks $35-37$ and post partum were analysed because some patients delivered before week 38 and some contracted intrahepatic cholestasis after week 34.)

There were significant positive correlations between serum selenium concentrations and glutathione peroxidase activities (fig 2) during weeks $35-37(r=0.69, p<0.001)$ and weeks 38-41 of pregnancy $(r=0.66, p<0.01)$, and post partum $(r=0.65, p<0.001)$.

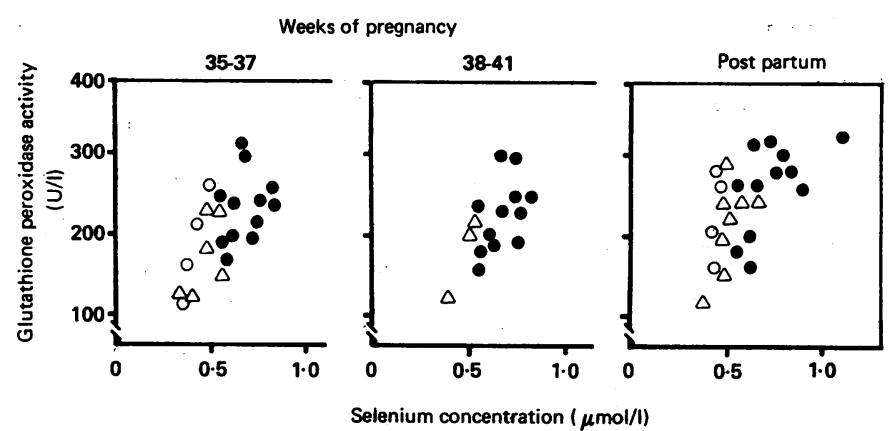

FIG 2-Correlation of serum selenium concentration with serum glutathione peroxidase activity during weeks 35-37 and 38-41 of pregnancy and post partum in patients with intrahepatic cholestasis of pregnancy who had singleton $(\triangle)$ and twin $(\mathrm{O})$ births and women who had normal pregnancies $(\Theta)$.

\section{Discussion}

Oestrogens may disturb intracellular biliary metabolism, but the mechanism is not clear. ${ }^{2}$ Pathological changes in the cellular membranes may primarily be responsible for the injury, ${ }^{128}$ which resembles that induced by free radicals. ${ }^{90}$ In normal pregnancy antioxidants prevent the oxidative damage of oestrogens, but in patients with intrahepatic cholestasis of pregnancy in our study the concentration of selenium and the activity of glutathione peroxidase, an essential factor in antioxidation, were low. The antioxidative defence may have been defective, as glutathione peroxidase reduces concentrations of steroid hydroperoxides ${ }^{11}$ and other peroxides. ${ }^{1213}$ In patients with intrahepatic cholestasis of pregnancy the reduced activity of glutathione peroxidase and possibly disturbed function of the microsomal cytochrome P-450 system, also controlled by selenium, ${ }^{14}$ may lead to the formation of free radicals, ${ }^{15}$ which could damage the hepatocytes and reduce excretion of bile..$^{17-19}$

As pregnancy advances selenium concentrations usually decrease, but this causes no harm if the body's storage and nutritional intake of selenium are normal. ${ }^{20}$ Twin pregnancy is a risk factor for intrahepatic cholestasis of pregnancy, ${ }^{21}$ as the excessive oestrogen load increases the requirement for hepatic antioxidative capacity,

TABLE II-Mean (SD) serum concentrations of selenium and activities of glutathione peroxidase in controls and patients with intrahepatic cholestasis of pregnancy during different periods in last trimester of pregnancy and post partum.

\begin{tabular}{|c|c|c|c|c|c|c|c|c|}
\hline & \multicolumn{4}{|c|}{ Serum selenium concentration $(\mu \mathrm{mol} / \mathrm{l})$} & \multicolumn{4}{|c|}{ Serum glutathione peroxidase activity (U/l) } \\
\hline & \multicolumn{3}{|c|}{ Weeks of pregnancy } & \multirow[b]{2}{*}{ Post partum } & \multicolumn{3}{|c|}{ Weeks of pregnancy } & \multirow[b]{2}{*}{ Post partum } \\
\hline & $30-34$ & $35-37$ & $38-41$ & & $30-34$ & $35-37$ & $38-41$ & \\
\hline & \multicolumn{3}{|c|}{$\square^{\star \star \star} \longrightarrow$} & & \multicolumn{2}{|c|}{$\square^{*}-$} & & \\
\hline $\begin{array}{l}\text { Controls }(n=10)^{\star} \\
\text { Patients with intrahepatic cholestasis of pregnancy }(n=11)\end{array}$ & $0.74(0.07)$ & $\begin{array}{l}0.65(0.08) \\
0.46(0.11)\end{array}$ & $0.65(0.09)$ & $\begin{array}{l}0 \cdot 70(0 \cdot 17) \\
0 \cdot 49(0 \cdot 07)\end{array}$ & $267(47)$ & $\begin{array}{l}245(46) \\
182(53)\end{array}$ & $230(52)$ & $\begin{array}{l}264(63) \\
213(56)\end{array}$ \\
\hline
\end{tabular}

${ }^{\star} \mathrm{p}<0.05, \star \star \mathrm{p}<0.01$.

${ }^{\star} \mathrm{p}<0 \cdot 05, \star \star \mathrm{p}<0 \cdot 01$.
$\dagger$ Two controls were excluded because they did not have recordings for each period. 
which, with the marginal selenium availability in Finland, often fails in twin pregnancy. The possibility that increased metabolism of selenium, similar to that seen in the liver disease caused by valproic acid, ${ }^{22}$ or malabsorption due to cholestasis, ${ }^{23}$ might be responsible for the low serum concentrations of selenium in patients with this disease seems unlikely as the selenium concentrations were already low when the disease first manifested.

This study provides indirect evidence that the capacity of the liver to metabolise the products of hepatic oxidation - that is, the hepatic antioxidative defence mechanism - of oestrogens in patients with intrahepatic cholestasis of pregnancy may be impaired. This may lead to structural and functional damage to the hepatocytes, resulting in cholestasis.

We thank Miss Kaija Aura for her skilful technical help.

\section{References}

1 Kern F Jr, Erfling W, Simon FR, et al. Effect of estrogens on the liver. Gastroenterology 1978;75:512-22.

2 Schreiber AJ, Simon FR. Estrogen induced cholestasis: clues to pathogenesis and treatment. Hepatology 1983;3:607-13.

3 Agostini A, Gerli GC, Beretta L, et al. Erythrocyte antioxidant enzymes and selenium serum levels in an Andean population. Clin Chim Acta 1983;133:153-7.

4 Schwarz K. Essentiality and metabolic functions of selenium. Med Clin North Am 1976;60:745-58.

5 Muth OH, Weswig PH, Whanger PD, Oldfield JE. Effect of feeding selenium-deficient ration to the subhuman primate (Saimiri sciureus). Am $\mathcal{f}$ Vet Res 1971;32:1603-5.

6 Korpela H, Kumpulainen J, Luoma PV, Arranto AJ, Sotaniemi EA. Decreased serum selenium in alcoholics as related to liver structure and function. Am $\mathcal{F} \mathrm{Clin} N u t r$ 1985;42:147-51.

7 Mutanen M, Koivistoinen P. The role of imported grain on the selenium intake of Finnish population in 1941-1981. Int 7 Vitam Nutr Res 1983;53:102-8.
8 Scherlock S. Patterns of hepatocyte injury in man. Lancet 1982;i:782-6.

9 Dormandy TL. Free radical oxidation and antioxidants. Lancet 1978;i:647-50.

10 Slater TF. Free-radical mechanisms in tissue injury. Biochem $\mathcal{f}$ 1984;222:1-15. 10 Slater TF. Free-radical mechanisms in tissue injury. Biochem $\mathcal{f}$ 1984;222:1-15.

12 Ursini F, Maiorino M, Gregolin C. The selenoenzyme phospholipid hydroperoxide $C$ glutathione peroxidase. Biochim Biophys Acta 1985;839:62-70

13 Sies H, Graf P, Cadenas E. Hydroperoxide reduction in liver cells: calcium release and $\widehat{\Omega}$ relationship to arachidonate metabolism. In: Braquet $P$, Gavay RP, Frölich JC, Nicosia $S$, eds. Prostaglandins and membrane ion transport. New York: Raven Press, 1985:119-28. 각. 14 Burk RF, Masters BSS. Some effects of selenium deficiency on the hepatic microsomal $\mathbb{D}$ cytochrome P-450 system in the rat. Arch Biochem Biophys 1975;170:124-31.

15 Marks F, Hecker E. Metabolism and mechanism of action of oestrogens. XII. Structure TI and mechanism of formation of water-soluble and protein-bound metabolites of $\varrho$ oestrogens in rat liver microsomes in vitro and in vivo. Biochim Biophys Acta 1969;187:250-65.

16 Nelson SD, Mitchell JR, Dybing E, Sasame HA. Cytochrome P-450-mediated oxidation $\stackrel{\mathscr{C}}{\rightarrow}$ of 2-hydroxyestrogens to reactive intermediates. Biochem Biophys Res Commun 1976;70:음 1157-65.

17 Akerboom TPM, Bilzer M, Sies $H$. Relation between glutathione redox changes and $\overline{\bar{N}}$ biliary excretion of taurocholate in perfused rat liver. $\mathcal{F}$ Biol Chem 1984;259:5838-43.

18 Phillips MM, Oda M, Mak E, Fisher MM, Jeejeebhoy KN. Microfilament dysfunction as $\overparen{\mathbb{D}}$ a possible cause of intrahepatic cholestasis. Gastroenterology 1975;69:48-58.

19 Smith MT, Thor H, Jewell SA, Bellomo G. Sandy MS, Orrenius S. Free radical induced changes in the surface morphology of isolated hepatocytes. In: Armstrong D, Sohal RS, Gutlwe RG, Slater TF, eds. Free radicals in molecular biology, aging, and disease. $\vec{O}$ New York: Raven Press, 1984: 103-18.

20 Butler JA, Whanger PD, Tripp MM. Blood selenium and glutathione peroxidase activity $\overrightarrow{\vec{\omega}}$ in pregnant women. Comparative assays in primates and other animals. Am $\mathcal{F}$ Clin Nutr 1982;32:15-23.

21 Kauppila A, Jouppila P, Ylikorkala O, Koivisto M, Moilanen I. Twin pregnancy: $\frac{O}{3}$ a clinical study of 335 patients. Acta Obstet Gynecol Scand [suppl] 1975;44:5-12.

22 Hyrd RW, Van Rinsvelt HA, Wilder BJ, Meanhaut W, De Reu. L. Selenium, zinc, and copper changes with valproic acid: possible relation to drug side effects. Neuralogy 1984;34:1983-5.

23 Ward KP, Arthur JR, Russell G, Aggett PJ. Blood selenium content and glutathione of peroxidase activity in children with cystic fibrosis, coeliac disease, asthma, and epilepsy. of Eur 7 Pediatr 1984;142:21-4.

\title{
Relation between phenotype and banal melanocytic naevi
}

\author{
J S C ENGLISH, A J SWERDLOW, R M MACKIE, C J O'DOHERTY, J A A HUNTER, \\ J CLARK, D J HOLE
}

\begin{abstract}
In a study of risk factors for the development of melanocytic naevi in relation to the pathogenesis of malignant melanoma 197 white adults were examined by four dermatologists and naevus counts correlated with several other features. Highly significant associations were found between large numbers of banal acquired melanocytic naevi and the ability to tan easily without burning (skin types 3 and 4; relative risk 4.6), brown or hazel eyes (relative risk 3.5), green or grey eyes (relative risk 3.5), and brown or black hair (relative risk 3.7). No significant associations with numbers
\end{abstract}

\section{University of Glasgow}

J S C ENGLISH, MB, MRCP, registrar, department of dermatology

A J SWERDLOW, PHD, MFCM, senior lecturer, department of community medicine

R M MACKIE, FRSE, FRCPATH, professor, department of dermatology

J CLARK, BSC, research assistant, department of community medicine

Department of Dermatology, University of Edinburgh

C J O'DOHERTY, MSC, MRCP, lecturer

J A A HUNTER, MD, FRCPED, professor

West of Scotland Cancer Surveillance Unit, Glasgow

D J HOLE, MSC, senior statistician

Correspondence to: Professor R M MacKie, Department of Dermatology, University of Glasgow, Glasgow G12. of naevi were shown for parity or use of oral contraceptives or other steroid hormones.

This is the first study to find any relation between melanocytic naevi and phenotypic factors in a white population.

\section{Introduction}

Interest in the possible relation between melanocytic naevi and $\mathrm{O}$ malignant melanoma was stimulated by the description by Elder and colleagues of the so called "dysplastic naevus syndrome." Recent studies have shown that large numbers of "banal" acquired $\frac{7}{0}$ naevi are a strong risk factor for melanoma. ${ }^{2.4}$ The magnitude of this risk is much greater than for any other risk factor so far established, $N$ and thus the aetiology and epidemiology of naevi are currently $\omega$ important topics of investigation. There is at present very little published information on factors leading to the development ofe naevi.

Several studies have been reported of numbers of naevi in the $\stackrel{?}{+}$ newborn ${ }^{5-7}$ and in children and adults. ${ }^{7-11}$ These show that naevi are $\frac{0}{0}$ rarely present at birth, increase in number at puberty, and are much $\stackrel{\vec{\Phi}}{\vec{\Phi}}$ less numerous in subjects over 40 . The increase in the number of $\stackrel{?}{\overparen{P}}$ naevi at around puberty suggests that hormonal factors may be $\varnothing$ important. The existence of chloasma, increase in pigmentation, and darkening of naevi during pregnancy ${ }^{12}$ and the detection of $\varnothing$ oestrogen and progesterone receptors on naevi ${ }^{13}$ also suggest a음 relation between naevi and hormonal stimulation. One study reported that systemic administration of corticotrophin and corti- 